\title{
Wave Trains of 10-30-Day Meridional Wind Variations over the North Pacific during Summer
}

\author{
LEI DU ${ }^{\mathrm{a}, \mathrm{b}}$ AND RIYU Lu ${ }^{\mathrm{a}, \mathrm{b}}$ \\ ${ }^{a}$ State Key Laboratory of Numerical Modeling for Atmospheric Sciences and Geophysical Fluid Dynamics, Institute of Atmospheric \\ Physics, Chinese Academy of Sciences, Beijing, China \\ ${ }^{\mathrm{b}}$ College of Earth and Planetary Sciences, University of the Chinese Academy of Sciences, Beijing, China
}

(Manuscript received 2 February 2021, in final form 27 August 2021)

\begin{abstract}
The present study investigates the intraseasonal oscillations over the North Pacific during summer based on the ERA-Interim reanalysis dataset. It is shown that the main component of intraseasonal variations in meridional wind is dominated by 10-30-day variability. Zonally oriented wave trains are identified over the North Pacific at this band, with a zonal wavenumber 6 . The wave trains exhibit an equivalent-barotropic structure, with the maximum amplitude in the upper troposphere, and are manifested as quasi-stationary Rossby waves with the energy dispersing eastward. The wave trains do not show a phase-locking feature; that is, they have no preferred geographical locations in the zonal direction. Furthermore, energy analyses suggest that the intraseasonal waves gain energy through baroclinic energy conversion, while the barotropic energy conversion plays a negligible role. The present results have implications for better understanding and forecasting weather and climate in North America, since the intraseasonal waves over the North Pacific may act as precursory signals for extreme events occurring over North America.
\end{abstract}

KEYWORDS: Atmospheric circulation; Climate variability; North Pacific Ocean; Rossby waves

\section{Introduction}

Intraseasonal oscillations (ISOs), which span a range of 10 90 days, exist in both the tropics and extratropics. They were first identified as 30-60-day oscillations of atmospheric convection in the tropics by Madden and Julian (1971), which triggered various studies on ISOs. As one of the most prominent lowfrequency signals, the ISOs have important impacts on the global weather and climate, such as monsoons (Ding and Wang 2007; Wheeler et al. 2009; Zhang 2013; Jiao et al. 2019), tropical cyclones (Ferreira et al. 1996; Maloney and Hartmann 2000; Hall et al. 2001; Ho et al. 2006; Jiang et al. 2012), precipitation (Jeong et al. 2008; Zhang et al. 2009; He et al. 2011; Jia et al. 2011; Teng and Branstator 2017), surface air temperature (Jeong et al. 2005; L'Heureux and Higgins 2008; Park et al. 2010; Teng et al. 2013), and so on. Furthermore, as ISOs are considered to be a major source of subseasonal predictability, understanding their dynamics is an important task for subseasonal-to-seasonal prediction, which can bridge the gap between weather and climate (Vitart et al. 2012).

The ISOs in the extratropics, compared with their tropical counterparts (e.g., Yasunari 1979; Wang et al. 2006), are prone to vagary. The complexity of extratropical ISOs is mainly embodied in the following aspects. First, there is a great diversity in the concerned periodicity (Stan and Krishnamurthy 2019), varying from 10-20 days (Wei et al. 2019) to 10-90 days (Zhang and Ren 2017). Second, the ISOs in the extratropics have obvious regional characteristics, which have been found in various studies focusing on certain regions, such as Eurasia (Ding and Wang 2007; Fukutomi et al. 2012; Yang et al. 2013; Kong et al. 2017; Jiao et al. 2019), North America (Mo 1999;

Corresponding author: Riyu Lu, 1r@mail.iap.ac.cn
Jiang and Lau 2008; Wei et al. 2019), the North Atlantic (Plaut and Vautard 1994; Doblas-Reyes et al. 1998; Simonnet and Plaut 2001), and the North Pacific (Elsner 1992; Marcus et al. 1996; Yao et al. 2016). Finally, the extratropical ISOs exhibit distinctive characteristics between seasons. For example, in Eurasia, the extratropical ISOs generally propagate eastward in winter (Yang and Li 2016; Yao et al. 2018; Jiao et al. 2019), whereas they tend to propagate either eastward (Ding and Wang 2007; Fukutomi et al. 2012) or southeastward (Liu et al. 2012; Kong et al. 2017) or westward (Yang et al. 2013) in summer.

The North Pacific is one of the regions in the extratropics with significant ISOs, and the ISOs over there have been specially investigated. The previous studies examined different periods of ISOs over the North Pacific, such as 10-30 days (Kushnir 1987; Alexander and Scott 1997; Ren et al. 2017; Xin et al. 2017) and 30-60 days (Plaut and Vautard 1994; Xiong et al. 2019). Furthermore, previous studies indicated that the ISOs over the North Pacific exhibit contrasting propagation patterns, including eastward propagation (Alexander and Scott 1997), westward propagation (Kushnir 1987; Xin et al. 2017), or nonpropagating (Dai et al. 2017; Xiong et al. 2019). These differences in ISOs over the North Pacific mainly result from different research objects in previous studies, such as intraseasonal variability of surface flux (Alexander and Scott 1997) or the Aleutian low (Xiong et al. 2019). In association with these differences, different mechanisms were proposed for the growth and maintenance of ISOs, including both barotropic and baroclinic energy conversion and interactions with high-frequency eddies (Kushnir 1987; Hsu 1996; Zhang and Ren 2017). For instance, Kushnir (1987) suggested that both baroclinic and barotropic conversions contribute to the growth of low-frequency disturbances with a period of about 3 weeks. More recently, Zhang and Ren (2017) demonstrated that 
synoptic transient eddy forcing is beneficial to establish and maintain the ISOs of Aleutian low. However, almost all of these studies focus on the winter season.

Some studies investigated summer ISOs over the North Pacific. Kawamura et al. (1996) suggested that convection in the western tropical Pacific can trigger extratropical ISOs over the North Pacific. Wang et al. (2013) examined the 10-50-day oscillations of upper-tropospheric streamfunction over the North Pacific during May-October, and showed that the meridional eddy vorticity transport plays a major role in the growth of ISOs over the eastern North Pacific. Their further results indicate that the ISOs propagate westward and reach their maximum amplitudes at about $150^{\circ} \mathrm{W}$. Both of them suggested that ISOs can gain energy from the mean state through barotropic energy conversion. Most recently, Zhu et al. (2020) investigated the quasi-biweekly Pacific-Japan pattern, which is a dominant teleconnection pattern over the western North Pacific and East Asia during summer (Nitta 1987; Huang and Sun 1992), and suggested that the convective activities in the tropical western North Pacific could excite Rossby waves and the waves propagate northward into North Pacific. Unlike Kawamura et al. (1996) and Zhu et al. (2020), however, Wang et al. (2013) suggested that the local processes play a major role in ISOs over the North Pacific and the tropical forcings play a minor role.

In particular, Ambrizzi et al. (1995) investigated the teleconnection patterns over the entire globe during the boreal summer, and suggested that there is a waveguide belt near $40^{\circ} \mathrm{N}$ around almost the entire Northern Hemisphere, including the North Pacific, Eurasia, and North America. The 200-hPa streamfunction variability on the time scale of 10-30 days has been focused on in their study. The band of 10-30 days is to be shown in section 3 as the dominant period of 200-hPa meridional wind variability over the North Pacific during summer, and thus this band is also the period of concern in the present study. Ambrizzi et al. (1995) explained these teleconnection patterns through the waveguide effect of climatological upper-tropospheric westerly jet (Hoskins and Ambrizzi 1993). Some questions remain unknown. What are the essential features of the ISOs over the North Pacific during summer, including their dominant period, shape, and propagation? What the physical mechanisms responsible for the maintenance of intraseasonal teleconnection over the North Pacific? These questions are the main motivations of this study.

The meridional winds are mainly used in this study to depict the ISOs over the North Pacific during summer. Compared with other elements, the meridional wind is particularly well suited for capturing zonal wave trains (e.g., Lu et al. 2002; Wirth et al. 2018). In this study, therefore, we analyze ISOs by using 200-hPa meridional winds and identify zonally oriented wave trains on the intraseasonal time scale over the North Pacific during summer. Furthermore, we investigate the features and maintenance mechanism of the wave trains.

The organization of the remaining text is as follows. Section 2 describes the datasets and methods used in this study. Section 3 explores the features of the intraseasonal variability of upperlevel meridional winds over the North Pacific in summer, as well as other seasons for comparison. Section 4 defines the wave trains and investigates their characteristics. Section 5 explores the maintenance mechanism of the wave trains. Finally, section 6 presents conclusions and discussion.

\section{Data and methods}

This study uses daily mean data from the global European Centre for Medium-Range Weather Forecasts (ECMWF) Interim reanalysis dataset (ERA-Interim; Dee et al. 2011). The analysis period is 1979-2017, and the daily climatology of a particular day is calculated by averaging the corresponding daily-mean values over the 39 years. The present study focuses on intraseasonal variations, and the intraseasonal signals in the 10-30-day period and 10-90-day period are extracted by use of the Lanczos bandpass filter (Duchon 1979) with 201 weights on the daily anomalies, which are obtained by removing the climatological daily mean. A two-tailed Student's $t$ test is used to assess statistical significance. Considering the effect of autocorrelations on significance tests, the degrees of freedom for the sample are replaced by the degrees of effective freedom, which are calculated by the method of Zwiers and Storch (1995).

\section{Dominant time scale of intraseasonal variations over the North Pacific}

Figure 1 shows the standard deviations of 10-90-day meridional winds at $200 \mathrm{hPa}$ in spring (March-May), summer (June-August), autumn (September-November), and winter (December-February), respectively. The standard deviations are large in the extratropics regardless of season, particularly over the North Pacific, North America, and North Atlantic, and are relatively smaller over the midlatitude Eurasian continent. The standard deviations show a unique feature in summer: The large values tend to be concentrated in a band of $35^{\circ}-60^{\circ} \mathrm{N}$ over the North Pacific. In addition, the $10-90$-day component can explain about $40 \%-50 \%$ of the total variance of meridional winds at $200 \mathrm{hPa}$ at the band of $35^{\circ}-60^{\circ} \mathrm{N}$ over the North Pacific, and the ratios of variance of 10-90-day meridional wind at $200 \mathrm{hPa}$ to the total daily variance in summer are larger than those in other seasons (not shown), which may be in association with relatively weaker storm tracks in summer.

To reveal the dominant periodicity, a power spectral analysis was performed on the $200-\mathrm{hPa}$ meridional winds averaged over the region of $45^{\circ}-50^{\circ} \mathrm{N}, 160^{\circ}-170^{\circ} \mathrm{W}$ (black rectangle marked in Fig. 1b), where the maximum standard deviations appear in summer. Prior to the power spectrum analysis, the fluctuations with period below 5 days were moved by 5-day running means. The power spectrum displays peaks in the band of 10-30 days, and this band reaches the $95 \%$ significance level (Fig. 2). On the other hand, the band of 30-60 days displayed in the power spectrum plot is marginally significant. This result suggests that the 10-30-day oscillations represent the main component of intraseasonal variability.

Figure 3 shows the standard deviations of 10-30-day filtered meridional winds at $200 \mathrm{hPa}$ in summer. The standard deviations of 10-30-day band are similar to those of 10-90-day band in terms of spatial distribution, merely with a slight decrease in the amplitude. The 10-30-day band explains more than two-thirds of 
(a) MAM std 10-90d V200

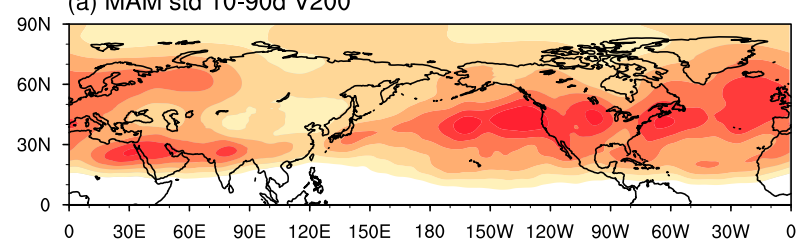

(b) JJA std 10-90d V200

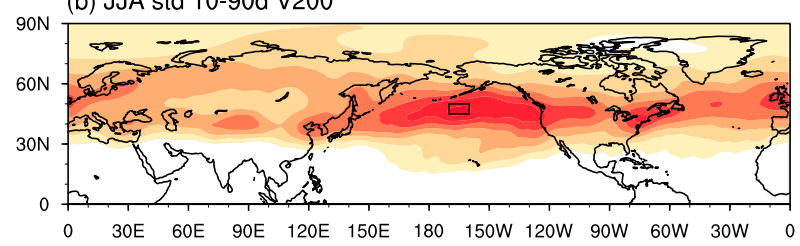

(c) SON std 10-90d V200

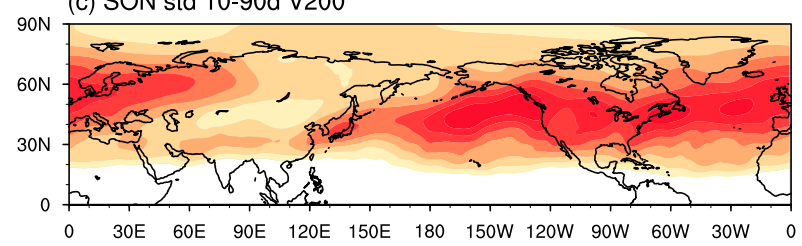

(d) DJF std 10-90d V200

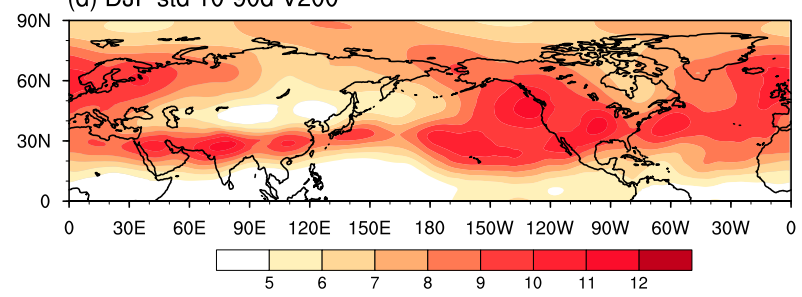

FIG. 1. Standard deviations of 10-90-day filtered meridional wind ( $\mathrm{m} \mathrm{s}^{-1}$ ) at the 200-hPa level during the boreal (a) spring (March-May), (b) summer (June-August), (c) autumn (September-November), and (d) winter (December-February). The box in (b) marks the summer 10-90-day activity center.

the variance of the 10-90-day band over the North Pacific (not shown), confirming that the band of 10-30 days is the dominant component of intraseasonal variations. Therefore, in the following we focus on the 10-30-day oscillations over the North Pacific in summer.

\section{Wave trains of 10-30-day oscillations over the North Pacific}

Figure 4 shows the lead-lag one-point correlation maps of 200-hPa meridional wind anomalies with the base point located at $45.75^{\circ} \mathrm{N}, 168^{\circ} \mathrm{W}$, which has the largest standard deviation value of 10-30-day filtered meridional winds at $200 \mathrm{hPa}$ (dot marked in Fig. 3). The simultaneous correlation map (Fig. 4e) shows that there exists a zonally oriented wavelike structure with alternatively positive and negative correlation coefficients over the North Pacific. The central latitude of the wavelike pattern is approximately located at $45.75^{\circ} \mathrm{N}$, and the wavelength of it is about $60^{\circ}$ of longitude, suggesting its zonal scale is equivalent to wavenumber 6 . The lead-lag correlation maps show the time evolution of the wavelike pattern. At day -4 , the correlation coefficients are generally small and not well organized. In the subsequent days (from day -3 to day -1 ), the correlation

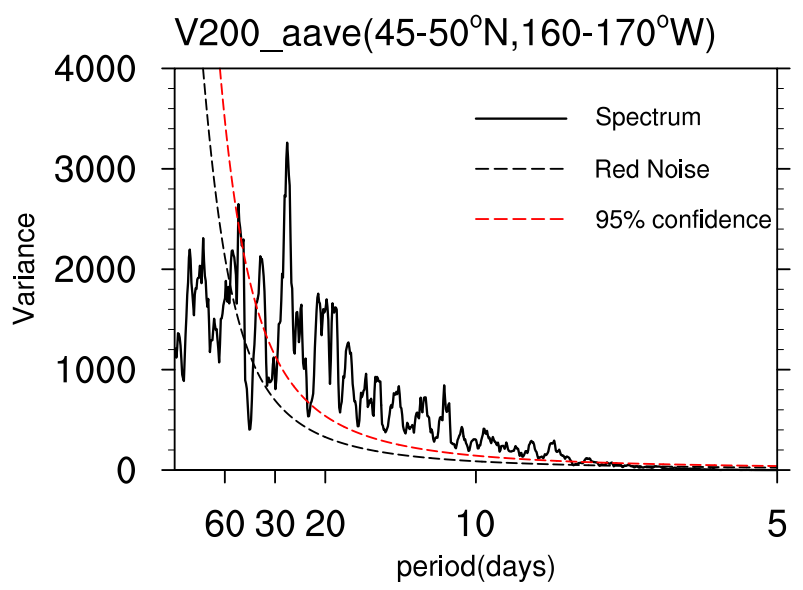

FIG. 2. Power spectral analysis of $200-\mathrm{hPa}$ meridional wind anomalies $\left(\mathrm{m}^{2} \mathrm{~s}^{-2}\right)$ averaged in the box marked in Fig. $1 \mathrm{~b}$ during summer. The black and red dashed lines represent red noise and the $95 \%$ significance level, respectively.

coefficients become intensified and appear as a well-organized wavelike pattern over the North Pacific, reach their maximum at day 0 , and then are weakened in the following days. The fact that the wavelike pattern is at its peak at day 0 and disappears at day -4 and day 4 implies a period of about 16 days, consistent with the period of 10-30 days focused on in this study. Furthermore, the anomalies tend to grow and decay earlier in the west than in the east, indicating that the wave train tends to propagate eastward through energy dispersion. This pattern is similar to that shown by Ambrizzi et al. (1995), who performed a lead-lag correlation analysis on the 200-hPa streamfunction with the base point being $40^{\circ} \mathrm{N}, 170^{\circ} \mathrm{W}$ (their Fig. 8).

Whether phase-locking or not is an important feature for wave trains is a question that needs to be further explored. Following Hong et al. (2018), we define the teleconnectivity by the area-weighted average of squared values of correlation coefficients within the domain $35^{\circ}-60^{\circ} \mathrm{N}, 120^{\circ} \mathrm{E}-100^{\circ} \mathrm{W}$, the region with large standard deviations (Fig. 3). The correlation coefficients are calculated by using 10-30-day meridional wind anomalies at all the grids in the domain and at the base point. Accordingly, we obtain the teleconnectivity for the base point. Then, the base points are shifted along $45.75^{\circ} \mathrm{N}$ from $162^{\circ} \mathrm{E}$ to $138^{\circ} \mathrm{W}$, and this span of longitudes covers a

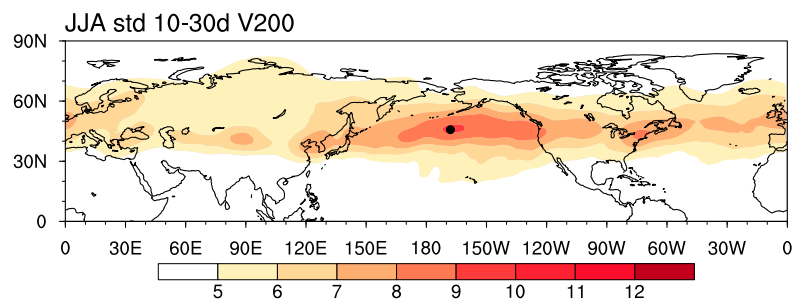

FIG. 3. Standard deviations of 10-30-day filtered meridional wind $\left(\mathrm{m} \mathrm{s}^{-1}\right)$ at the 200-hPa level during the summer (JuneAugust). The dot denotes the point of maximum standard deviation $\left(45.75^{\circ} \mathrm{N}, 168^{\circ} \mathrm{W}\right)$. 


\section{$45.75^{\circ} \mathrm{N}, 168^{\circ} \mathrm{W}$}

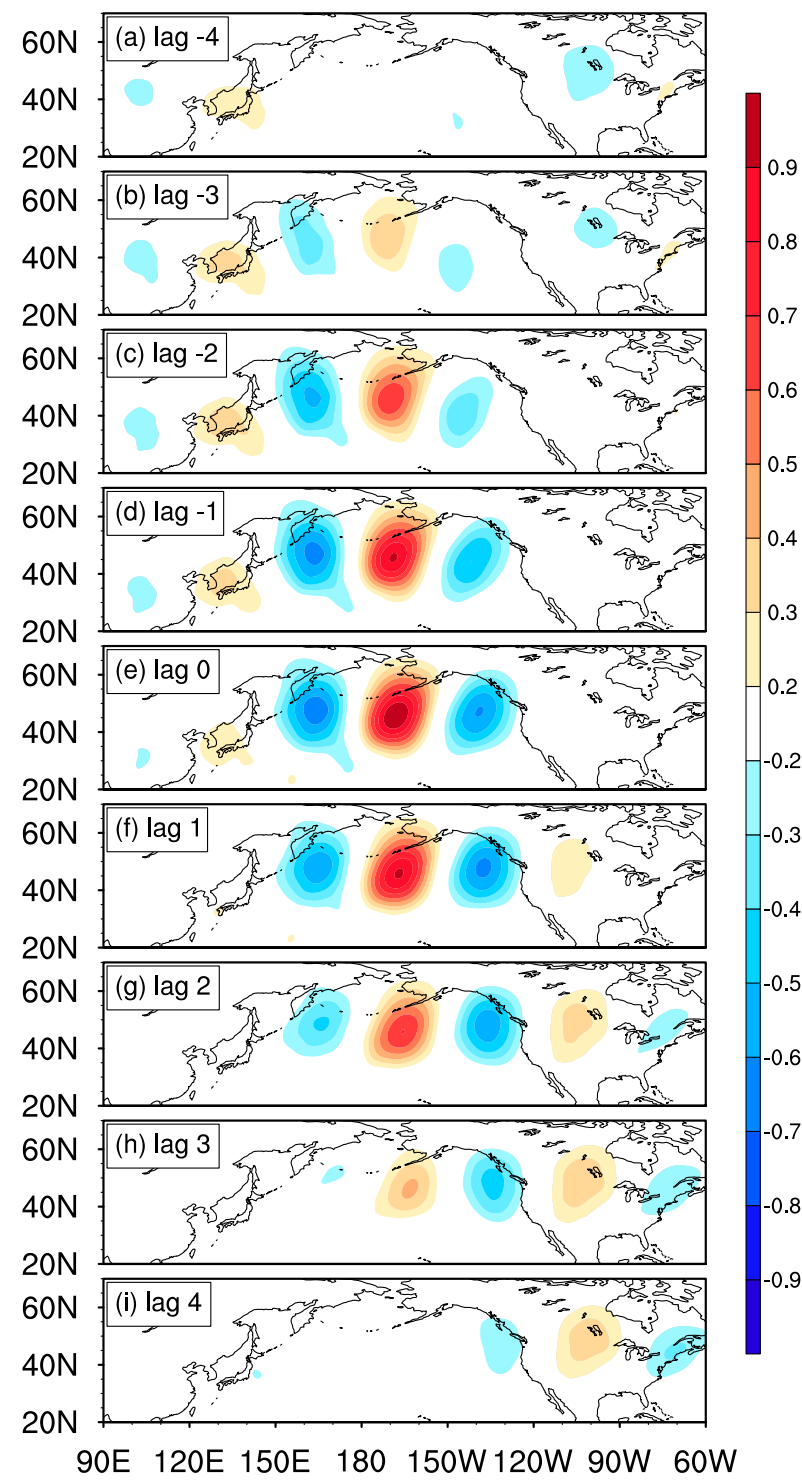

FIG. 4. Evolution of the one-point correlation maps of 10-30-day filtered 200 -hPa meridional wind anomalies between the base point $\left(45.75^{\circ} \mathrm{N}, 168^{\circ} \mathrm{W}\right)$ and every point from day -4 to day 4 . Only the absolute values of correlation coefficients greater than 0.2 and significant at the $95 \%$ confidence level are plotted.

wavelength, and the teleconnectivity distribution is shown in Fig. 5. If the teleconnectivity is high for a certain base point, it means that this point has strong correlations with other locations, suggesting that the wave obtained by this base point is strong. Teleconnectivity exhibits slight fluctuations between 0.113 and 0.135 , and this result suggests that the intraseasonal waves over the North Pacific do not have a clear phase-locking feature. Similar results were obtained with different domains.

To highlight the tripolar structure of intraseasonal waves in the North Pacific, a wave index is defined by using three nodes

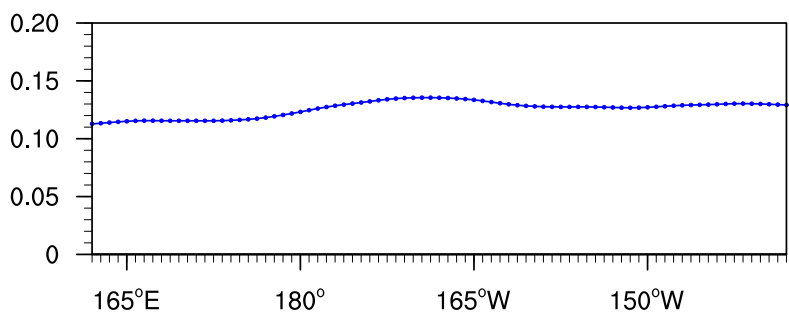

FIG. 5. Teleconnectivity of the wave trains defined in this paper. The latitude of the base point is $45.75^{\circ} \mathrm{N}$, and the longitude of the base point is marked on the abscissa. See the text for the details of teleconnectivity calculation.

of maximum and minimum anomalies, which are at the zonal interval of $30^{\circ}$ associated with the wavelength of $60^{\circ}$ longitude.

$$
\begin{aligned}
\text { index }= & {\left[V_{200}^{*}\left(45.75^{\circ} \mathrm{N}, 168^{\circ} \mathrm{W}\right)-V_{200}^{*}\left(45.75^{\circ} \mathrm{N}, 162^{\circ} \mathrm{E}\right)\right.} \\
& \left.-V_{200}^{*}\left(45.75^{\circ} \mathrm{N}, 138^{\circ} \mathrm{W}\right)\right] / 3,
\end{aligned}
$$

where $V_{200}^{*}$ indicates the 10-30-day filtered meridional wind anomalies at $200 \mathrm{hPa}$. The grid points selected here are the centers of the intraseasonal wave over the North Pacific (shown in Fig. 4e). However, it should be mentioned that since the waves are non-phase-locking (Fig. 5), the three grid points used to define the wave index can be shifted eastward or westward with their intervals being fixed at $30^{\circ}$.

Figure 6 shows 200-hPa meridional wind anomalies at 10-30-day band from day -4 to day 4 , regressed onto the normalized wave index defined above. The lead-lag regression plot (Fig. 6) highly resembles the lead-lag one-point correlation map (Fig. 4) in terms of spatial pattern, both displaying a zonally oriented wavelike structure over the North Pacific, confirming the existence of wave train over the North Pacific for 10-30-day oscillations. Furthermore, the wave train identified by regression analysis is also quasi-stationary, which can be illustrated by the stationarity of southerly anomalies around the Alaska Peninsula from day -3 to day 2, during which the clear wave train appears over the North Pacific. In addition, similar to Fig. 4, Fig. 6 also indicates that the wave train appears earlier over the northwest Pacific than over the northeast Pacific and North America, again suggesting the downstream dispersion of wave energy. Similar results are obtained when the wave train is zonally shifted (not shown).

Figure 7 displays the Hovmöller diagram of 10-30-day meridional wind anomalies at $200 \mathrm{hPa}$ along $45.75^{\circ} \mathrm{N}$ regressed onto the normalized wave index. The anomalies associated with the wave train are strongest along this latitude, particularly over the North Pacific (Figs. 4 and 6). The locations of positive and negative cells tend to shift slightly eastward but with a very slow speed, suggesting that the wave train is quasistationary. On the other hand, Fig. 7 also indicates the eastward propagation of wave energy, and the speed of energy dispersion is estimated to be about $40^{\circ}$ of longitude per day over the North Pacific, which is approximately 2 times the climatological zonal velocity over the North Pacific, in broad agreement with the theory of Rossby waves. In addition, similar results were obtained when the regression analysis was 


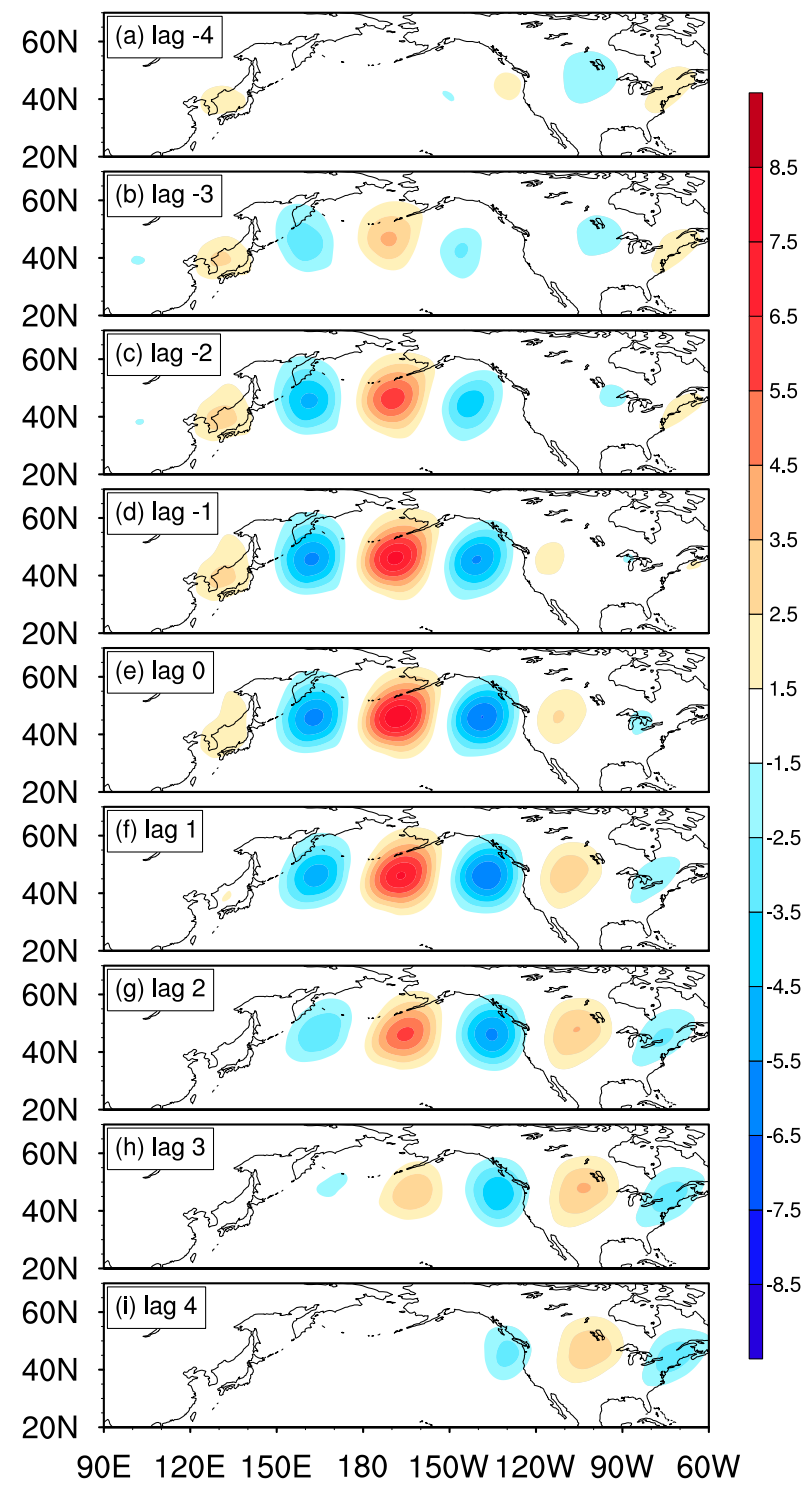

FIG. 6. The 10-30-day filtered meridional wind anomalies $\left(\mathrm{m} \mathrm{s}^{-1}\right)$ at $200 \mathrm{hPa}$ obtained by regression with respect to the normalized wave index (see text for the definition) from day -4 to day 4. Only the absolute values of wind anomalies greater than 1.5 and significant at the $95 \%$ confidence level are plotted.

performed by using base points shifted $15^{\circ}$ of longitude westward or eastward (not shown). In Fig. 7, there are two anticorrelated wave trains around \pm 7 days, which are artificially caused by the filtered band of 10-30 days.

Figure 8 shows the vertical cross section of meridional wind and temperature anomalies along $45.75^{\circ} \mathrm{N}$ regressed onto the normalized wave index. The wave shows an equivalentbarotropic structure, appearing in the entire troposphere and lower stratosphere, and the strongest anomalies appear in the upper troposphere between 200 and $250 \mathrm{hPa}$. In addition, the temperature anomalies also exhibit equivalent-barotropic characteristics, showing alternatively positive and negative centers in the troposphere and stratosphere, respectively. This

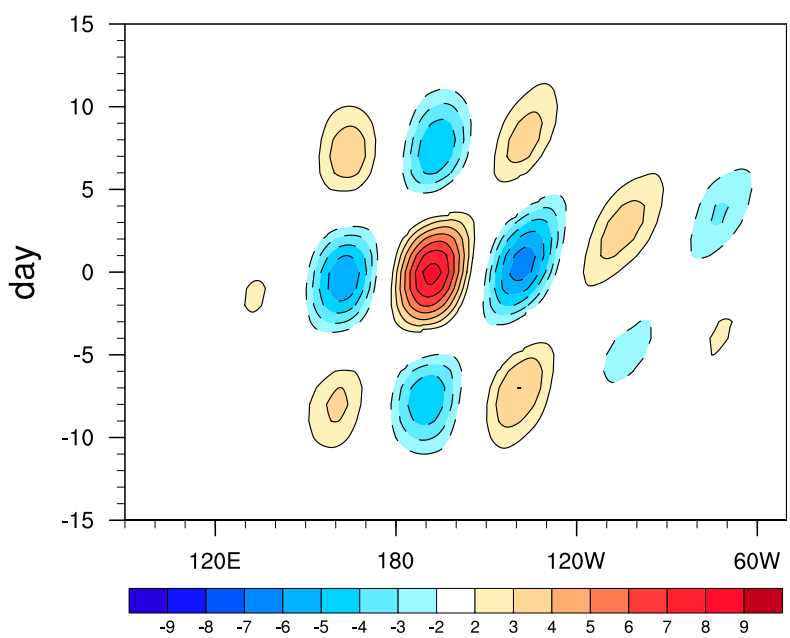

FIG. 7. The Hovmöller diagram of the 10-30-day filtered meridional wind anomalies $\left(\mathrm{m} \mathrm{s}^{-1}\right)$ at $200 \mathrm{hPa}$ along $45.75^{\circ} \mathrm{N}$ regressed onto the normalized wave index (see text for the definition). Only the anomalies that exceed the $95 \%$ significance level based on a two-tailed Student's $t$ test and where the absolute values of anomalies greater than 2 are plotted. The solid (dashed) lines represent the positive (negative) values.

distribution of temperature anomalies is closely related to the circulation anomalies, that is, higher (lower) temperatures correspond to anticyclonic (cyclonic) anomalies, which can be estimated by the meridional wind anomalies, in the troposphere, with the opposite correspondence in the stratosphere.

\section{Energetics of the wave trains}

Energetic analysis is performed in this section to explore the possible mechanism for growth and maintenance of the intraseasonal waves over the North Pacific. Efficiencies of the energy conversions are evaluated as the replenishing time scales:

$$
\begin{aligned}
\tau_{\mathrm{ck}} & =\{\mathrm{KE}\} /\{\mathrm{CK}\}, \\
\tau_{\mathrm{cp}} & =\{\mathrm{APE}\} /\{\mathrm{CP}\}, \\
\tau_{\mathrm{ck}+\mathrm{cp}} & =\{\mathrm{KE}+\mathrm{APE}\} /\{\mathrm{CK}+\mathrm{CP}\} .
\end{aligned}
$$

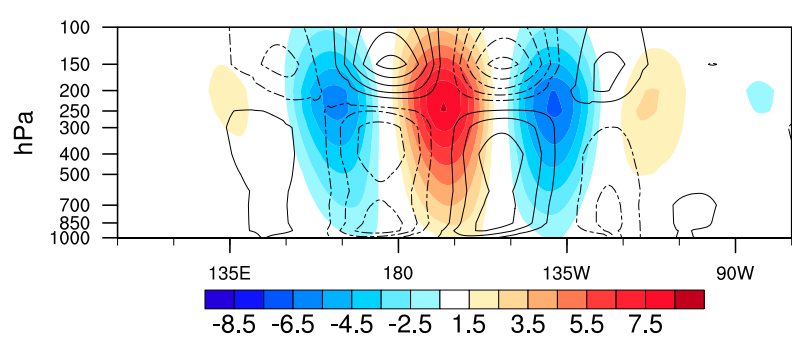

FIG. 8. Vertical cross section of 10-30-day filtered meridional wind anomalies (shading; $\mathrm{m} \mathrm{s}^{-1}$ ) and temperature anomalies (contour; K) along $45.75^{\circ} \mathrm{N}$ regressed onto the normalized wave index (see the definition in text) at day 0 . Contours are drawn with an interval of 0.4 , and positive (negative) lines are solid (dashed). Only anomalies significant at the $95 \%$ confidence level are plotted. 
A positive replenishing time scale indicates the net energy gain of waves, and a shorter replenishing time scale can be regarded as being effective for maintaining waves. Here, KE and CK denote perturbed kinetic energy and barotropic energy conversion, and APE and CP denote available potential energy and baroclinic energy conversion, respectively. The curly braces \{\} denote the spatial integration over the region $120^{\circ} \mathrm{E}-$ $60^{\circ} \mathrm{W}, 30^{\circ}-60^{\circ} \mathrm{N}$ and vertically from 1000 to $100 \mathrm{hPa}$. Choosing other integrated domains also yields qualitatively similar conclusions. These terms are defined as follows (e.g., Kosaka and Nakamura 2006; Kosaka et al. 2009; Hu et al. 2018; Xu et al. 2019):

$$
\begin{aligned}
\mathrm{CK} & =\frac{v^{\prime 2}-u^{\prime 2}}{2}\left(\frac{\partial \bar{u}}{\partial x}-\frac{\partial \bar{v}}{\partial y}\right)-u^{\prime} v^{\prime}\left(\frac{\partial \bar{u}}{\partial y}+\frac{\partial \bar{v}}{\partial x}\right), \\
\mathrm{CP} & =-\frac{f}{S}\left(v^{\prime} T^{\prime} \frac{\partial \bar{u}}{\partial p}-u^{\prime} T^{\prime} \frac{\partial \bar{v}}{\partial p}\right), \\
\mathrm{APE} & =\frac{R T^{\prime 2}}{2 S}, \\
\mathrm{KE} & =\frac{1}{2}\left(u^{\prime 2}+v^{\prime 2}\right),
\end{aligned}
$$

where $S$ is the static stability at the constant pressure, defined as $\left(R \bar{T} / C_{p} P\right)-(\partial \bar{T} / \partial p)$. Here, $C_{p}$ is the specific heat.

The total efficiencies of barotropic energy conversion $(\mathrm{CK})$ and baroclinic energy conversion (CP) from day -3 to day 1 (i.e., during the period of wave development and maturity) are shown in Fig. 9a. When the intraseasonal wave is represented by the normalized wave index, the time scale $\tau_{\mathrm{ck}+\mathrm{cp}}$ (white bars in Fig. 9a) is positive and less than 7 days from day -3 to day -1 (i.e., the period of wave development), whereas it is larger than 7 days during the period of wave maturity (day 0 and day 1 ). These results suggest that extracting energy from the basic flow through energy conversion is vital for the development of intraseasonal waves.

Figure 9a also shows the replenishing time scales for the intraseasonal waves represented by the zonally shifted wave indices. These "zonally shifted wave indices" are defined in the same way as the normalized wave index, but with all the three key points shifting eastward and westward by certain degrees longitude. For instance, a $15^{\circ}$ shifted index represents the modified wave index calculated by the key points at $45.75^{\circ} \mathrm{N}, 153^{\circ} \mathrm{W}$; $45.75^{\circ} \mathrm{N}, 177^{\circ} \mathrm{E}$; and $45.75^{\circ} \mathrm{N}, 123^{\circ} \mathrm{W}$, that is, eastward shifting $15^{\circ}$ in comparison with the normalized wave index. These modified indices are then used to calculate the corresponding energy conversion efficiencies. The results for $-15^{\circ},-7.5^{\circ}, 7.5^{\circ}$, and $15^{\circ}$, which are about $1 / 4$ and $1 / 8$ wavelengths, respectively, are shown in Fig. 9a. Regardless of westward or eastward shifting, the time scales do not change much. A clear increase of time scale appears only for the $15^{\circ}$ shifted index and at day 1 , but the time scale is larger than 7 days regardless of zonal shifting, suggesting that the total energy conversion is no longer efficient at this day (Fig. 9a). The efficiencies of total energy conversion, regardless of westward or eastward shifting of key points, support the non-phaselocking feature of the intraseasonal waves over the North Pacific shown in the preceding section. In addition, we calculated the efficiencies of baroclinic energy conversion (CP), which are
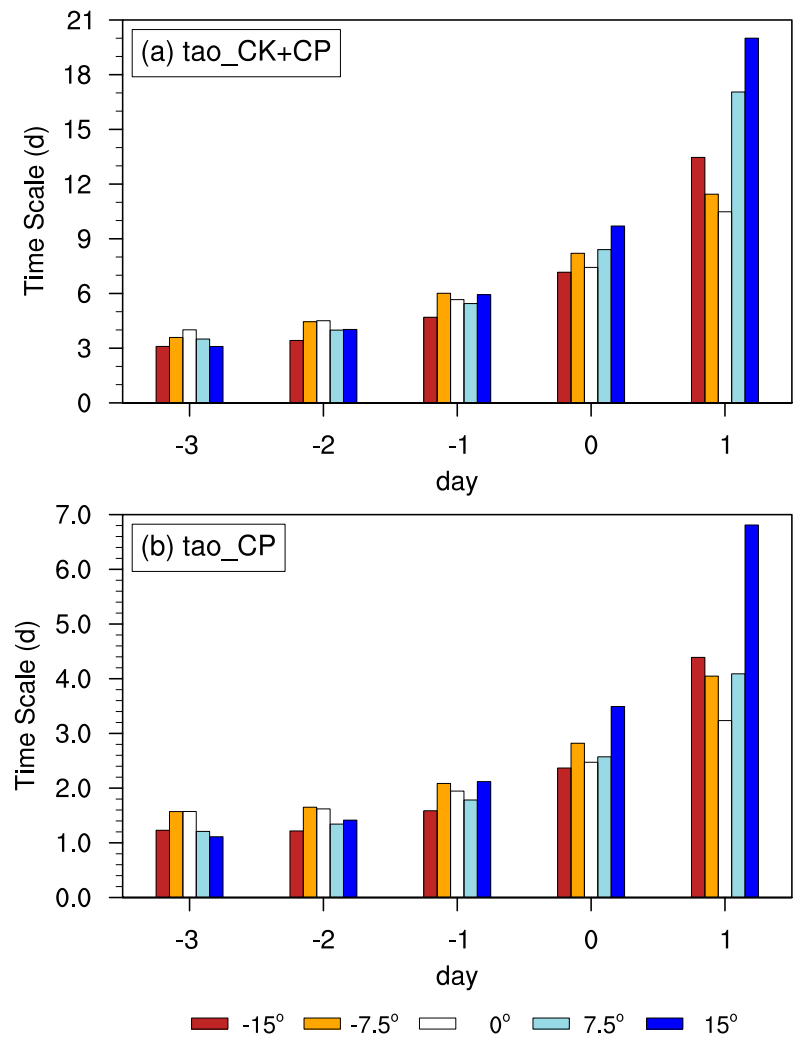

FIG. 9. The replenished time scales (day) associated with the wave trains over the North Pacific from day -3 to day 1 for (a) $\tau_{\mathrm{ck}+\mathrm{cp}}$ and (b) $\tau_{\mathrm{cp}}$. The replenished time scales are also evaluated after the anomaly pattern has been shifted zonally (see text for details). For instance, $-15^{\circ}$ denotes westward shifting $15^{\circ}$ of longitude, and $15^{\circ}$ denotes eastward shifting $15^{\circ}$ of longitude.

shown in Fig. 9b. It is found that the distribution of $\tau_{\mathrm{cp}}$ highly resembles $\tau_{\mathrm{ck}+\mathrm{cp}}$, only with differences in their values (i.e., $\tau_{\mathrm{cp}}$ is nearly one-third of $\left.\tau_{\mathrm{ck}+\mathrm{cp}}\right)$. Regardless of zonally shifting or not, $\tau_{\mathrm{cp}}$ is always positive and less than 7 days during day -3 to day 1 , suggesting that the baroclinic energy conversion is efficient and plays a dominant role for the development and maintenance of the intraseasonal waves. It is worth noting that the baroclinic energy conversion is still efficient during the mature phase of waves (day 0 and day 1 ), which is evidently distinct from the total energy conversion, implying that barotropic energy conversion might play a negative role in the development and maintenance of intraseasonal waves.

We also calculated the efficiencies of barotropic energy conversion, and found that the replenishing time scales, based on the normalized wave index, are either negative or larger than 27 days from day -3 to day 1 , with lowest positive value being 27.9 days at day -2 . Negative replenishing time scales suggest that waves cannot obtain energy from basic flows, and positive but large time scales suggest that barotropic energy conversion is too weak to overcome the dissipation of waves. Therefore, the result suggests that barotropic energy conversion plays a negligible role on the growth and maintenance of the intraseasonal waves. 
Figure 10 shows the horizontally and vertically integrated values of baroclinic energy conversion $\mathrm{CP}$ and its two terms from day -3 to day 1 . The value of $\mathrm{CP}$ increases during the growth period (from day -3 to day -1 ), reaches maximum on day -1 , and then decreases (Fig. 10a). In addition, shifting the key points eastward or westward does not change $\mathrm{CP}$ much from day -3 to day -1 , but weakens $C P$ at days 0 and 1 . The weakest of $\mathrm{CP}$ appears at day 1 with $15^{\circ}$ eastward shifting, consistent with the somewhat longer replenishing time scale shown in Fig. 9. These variations of $\mathrm{CP}$ are predominantly determined by its first term, $-(f / S) v^{\prime} T^{\prime}(\partial \bar{u} / \partial p)$, which is shown in Fig. 10b and correspond well to CP. The second term of CP, $(f / S) u^{\prime} T^{\prime}(\partial \bar{v} / \partial p)$, is much weaker and almost an order of magnitude smaller than its first term, suggesting that it plays a negligible role (Fig. 10c). This result indicates the important role of vertical shear of climatological zonal winds over the North Pacific in maintaining the intraseasonal waves.

A close inspection of Fig. 10a reveals that baroclinic energy conversion decreases during the mature period (from day 0 to day 1), particularly for the eastward shifting. The largest decrease occurs for the $15^{\circ}$ eastward shifting at day 1 , with $\mathrm{CP}$ being about half of that for the original wave index (i.e., without shifting). This weakness of $\mathrm{CP}$ may be attributed to weaker climatological upper-tropospheric westerlies in the eastern Pacific in comparison with western Pacific. The waves become weaker in the western Pacific and stronger in the eastern Pacific with the eastward shifting of wave indices, and their configuration with the climatological westerlies results in weaker CP. However, as mentioned before, baroclinic energy conversion is still effective even for the $15^{\circ}$ eastward shifting at day 1 , with the replenished time scale being lower than 7 days (Fig. 9b).

Figure 11 shows the horizontal spatial distributions of integrated APE and CP at day -1 when the CP is largest (Fig. 9a). The APE has two major positive centers over the North Pacific, corresponding to the larger temperature anomalies (Fig. 8). Around the two centers of APE, there exist four alternatively positive and negative centers of CP. A careful scrutiny shows that the positive centers are stronger than the negative ones with their values from upstream to downstream being $0.121,-0.094$, 0.123 , and $-0.077 \mathrm{~m}^{2} \mathrm{~s}^{-3} \mathrm{hPa}$, respectively. Similar results are obtained when the wave train is zonally shifted (not shown).

\section{Conclusions and discussion}

The present study investigates the intraseasonal oscillations over the North Pacific during summer (June-August) using the ERA-Interim daily data from 1979 to 2017. Strong intraseasonal oscillations of $200-\mathrm{hPa}$ meridional winds exist over a zonal band from roughly $35^{\circ}$ to $60^{\circ} \mathrm{N}$ over the North Pacific, which is distinct from other seasons, and their dominant period is 10-30 days. Hence, the present study focuses on 10-30-day intraseasonal variations over the North Pacific in summer.

Wave trains are identified over the North Pacific based on 200-hPa meridional wind variations at the band of 10-30 days. The wave trains are zonally oriented along the band of strong intraseasonal variance over the North Pacific, and their wavelengths are roughly about $60^{\circ}$ of longitude. The wave
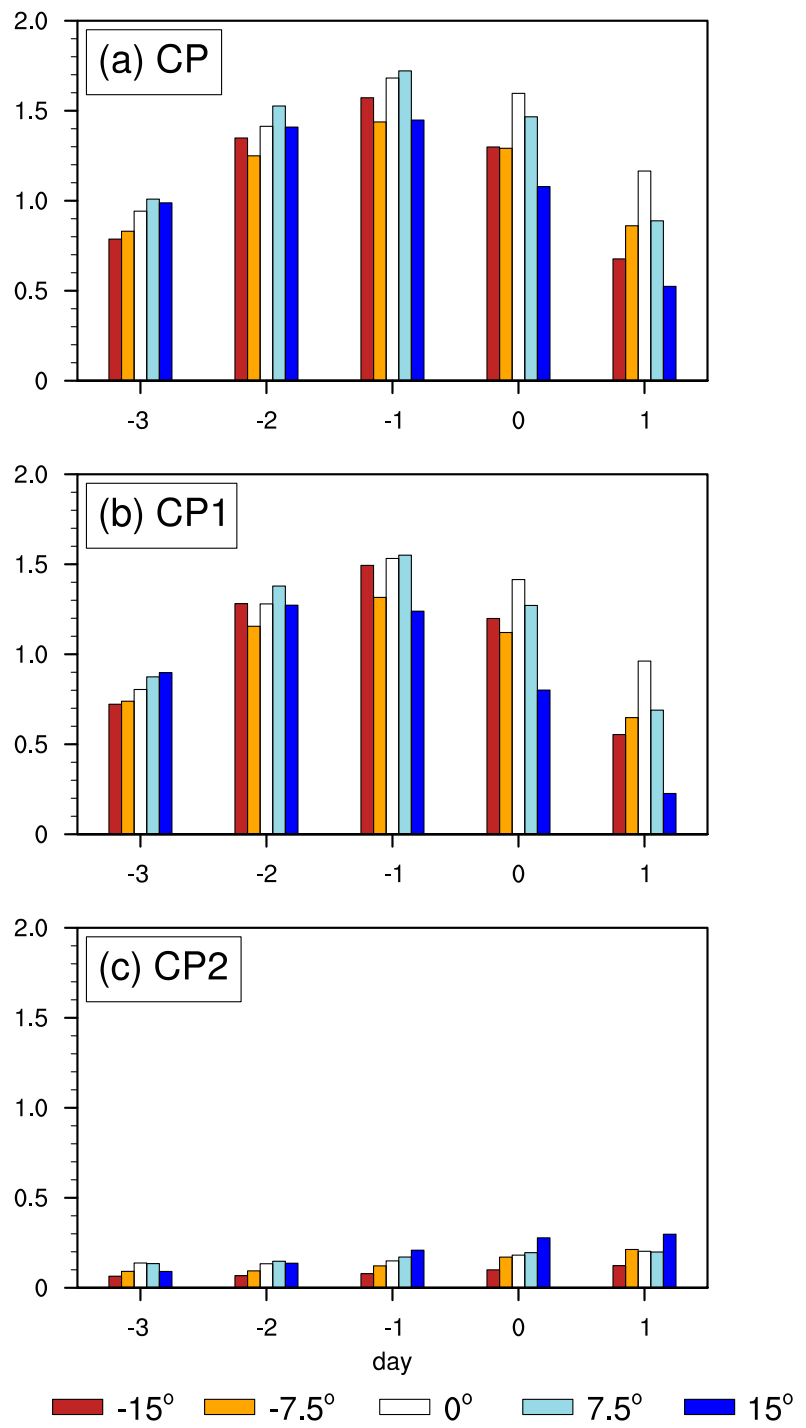

FIG. 10. As in Fig. 9, but for (a) the baroclinic energy conversion term (CP); (b) the first term of CP, $-(f / S) v^{\prime} T^{\prime}(\partial \bar{u} / \partial p)(\mathrm{CP} 1)$; and (c) the second term of $\mathrm{CP},(f / S) u^{\prime} T^{\prime}(\partial \bar{v} / \partial p)(\mathrm{CP} 2)$. Units are $10^{11} \mathrm{~m}^{4} \mathrm{~s}^{-3} \mathrm{hPa}$.

trains exhibit equivalent-barotropic structures, appearing over the entire troposphere and lower stratosphere with their maximum amplitudes appearing between 200 and $250 \mathrm{hPa}$. The life cycle of wave trains shows that they are quasistationary with a very slightly eastward phase shifting, and propagate eastward through energy dispersion at a speed of about $40^{\circ}$ per day, which is about 2 times the climatological zonal velocity over the North Pacific. Finally, the wave trains do not show a phase-locking feature; that is, the wave trains have no preferred locations for their activity cells, as noted also by Blackmon et al. (1984).

Furthermore, the growth and maintenance mechanisms of the wave trains are explored. The results indicate that the intraseasonal waves over the North Pacific can be maintained through baroclinic energy conversion. Further analysis suggests 


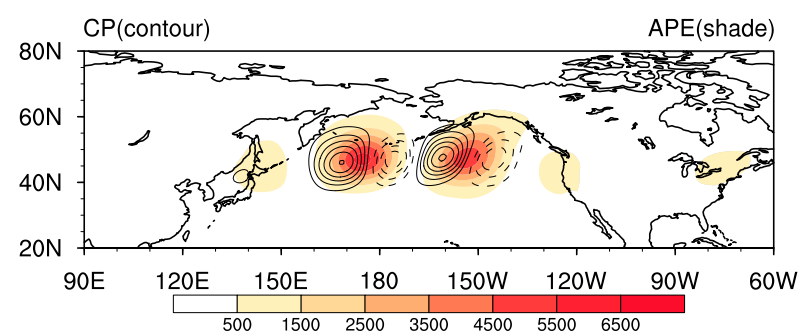

FIG. 11. The horizontal spatial distributions of vertically integrated APE (shading; $\mathrm{m}^{2} \mathrm{~s}^{-3} \mathrm{hPa}$ ) and $\mathrm{CP}$ (contour; $\mathrm{m}^{2} \mathrm{~s}^{-3} \mathrm{hPa}$ ) at day -1 as the wave zonally shifted $0^{\circ}$. The APE and CP are vertically integrated from 1000 to $100 \mathrm{hPa}$. Contour interval is 0.02 . The solid and dashed lines represent positive and negative values, and zero contours are omitted.

that baroclinic energy conversion is dominated by the term $-(f / S) v^{\prime} T^{\prime}(\partial \bar{u} / \partial p)$, while the term $(f / S) u^{\prime} T^{\prime}(\partial \bar{v} / \partial p)$ is an order of magnitude smaller and plays a negligible role. This implies that the vertical shear of climatological westerlies, which have a maximum velocity of about $20 \mathrm{~m} \mathrm{~s}^{-1}$ at $200 \mathrm{hPa}$ over the band of $40^{\circ}-50^{\circ} \mathrm{N}$ over the North Pacific (i.e., the band of strongest ISOs), plays a crucial role in maintaining the wave trains.

The intraseasonal wave trains over the North Pacific show clear distinctions from the so-called Silk Road pattern (SRP), which is the well-documented teleconnection pattern along the Asian westerly jet in summer (e.g., Lu et al. 2002; Enomoto et al. 2003; Sato and Takahashi 2003; Kosaka et al. 2009; and many others), although both of them are closely related to the waveguide of upper-tropospheric westerly jets (Ambrizzi et al. 1995). First, the wave trains over the North Pacific have a dominant period of 10-30 days, whereas the SRP is mainly on the interannual time scale. There are relatively larger standard deviations of 10-30-day oscillations along the Asian westerly jet $\left(\sim 40^{\circ} \mathrm{N}\right)$, but they are much smaller than those over the North Pacific (Fig. 3). Second, the wave trains over the North Pacific show a barotropic structure over the entire troposphere, while the SRP is confined to the upper troposphere. Third, the wave trains over the North Pacific do not show a phase-locking feature, while the SRP is phase-locked. This distinction can be explained by the difference in the maintenance mechanism: The wave trains are maintained by the baroclinic energy conversion, and the SRP by both the baroclinic and barotropic energy conversion. The barotropic energy conversion, which is dependent on the zonal structure of the climatological westerly jet, can explain the phase locking of SRP; that is, the teleconnection pattern can extract the kinetic energy from the mean flow more efficiently when its anomalous activity centers locate at preferred longitudes (Sato and Takahashi 2003; Kosaka et al. 2009). In-depth research of these distinctions is of great significance for better understanding of both the wave trains over the North Pacific and SRP.

The present results are based on the meridional winds, and it should be mentioned that the features of intraseasonal oscillations may be dependent on the elements used for analysis. We have repeated most of the analyses performed in this study, using geopotential heights at the same pressure level (i.e., $200 \mathrm{hPa}$ ), and found some appreciable differences with the present results. For instance, the intraseasonal dominant period obtained using geopotential heights is 10-60 days over the North Pacific (not shown), showing an extension into a longer time scale. In addition, the intraseasonal oscillations shown by geopotential heights tend to cover a broader scope $\left(20^{\circ}-70^{\circ} \mathrm{N}\right)$ in the meridional direction, and do not exhibit a clear feature of zonally oriented wave trains (not shown). Overall, the intraseasonal oscillations shown by meridional winds highlight the relatively small temporal and spatial scales and, more importantly, are characterized by the zonally oriented wave trains over the North Pacific. These discrepancies can be explained by the unique ability of meridional winds in capturing zonally oriented wave trains compared with zonal wind or other elements closely related to zonal wind, such as geopotential height, streamfunction, and vorticity, as suggested by Lu et al. (2002). The zonal winds may exhibit variability at large spatial scopes, particularly in the zonal direction, and thus filtering out the zonal winds can essentially emphasize on shorter scales both spatially and temporally.

The intraseasonal waves, which are focused on in this study, may have interactions with other time scale variations over the North Pacific. First, as the North Pacific is the region of active storm tracks, there would exist interactions between transient eddies and intraseasonal waves. We examined the effects of transient eddy forcing on the intraseasonal waves following Tanaka et al. (2016), and found that the transient eddies (28 days) have little effect on the maintenance of intraseasonal waves (not shown). However, this result does not refute the possibility that the intraseasonal waves have an impact on transient eddies. On the other hand, ENSO may act as an important factor affecting the interannual variability of intraseasonal waves, for it could modulate the seasonal-mean westerlies and their vertical gradient over the North Pacific through the Pacific-North America (PNA) pattern. This issue is currently under investigation. Similarly, the Pacific decadal oscillation (PDO) could also affect the decadal variations of intraseasonal waves.

Also, the present results have the following implications. The wave trains over the North Pacific identified in this study may have impacts on weather and climate in North America, such as heat waves, drought, and precipitation, as they propagate eastward into the region (Figs. 4 and 6). Some studies have reported that extreme climate events in North America can be induced by midlatitude waves as a result of internal atmospheric dynamics (Chen and Newman 1998; Teng et al. 2013; Teng and Branstator 2017; Lofverstrom 2020). From the view of intraseasonal variability of summer rainfall in North American, Jiang and Lau (2008) identified an upstream wave train in the upper troposphere over the North Pacific, and suggested that this wave train extends southwestward into the subtropical western North Pacific in the lower troposphere. It should be mentioned that the wave trains shown in these previous studies are distinct from those identified in this study. In addition, the wave trains over the North Pacific may also play a role in linking weather and climate between East Asia and North America: The anomalies over the former region, which have a significant component of intraseasonal variability, may trigger the wave trains over the 
North Pacific, and thus affect weather and climate in North America. Previous studies suggested the existence of such a linkage between the remote continents on the interannual time scale (e.g., Lau and Weng 2002). Therefore, understanding the intraseasonal waves over the North Pacific may be helpful for subseasonal forecasts in North America.

The present mechanism gives a hint that that similar intraseasonal wave trains may exist in other regions besides the North Pacific, particularly over the oceans in the Southern Hemisphere, as suggested by Ambrizzi et al. (1995). The strong climatological westerlies over these regions may also play a crucial role in maintaining intraseasonal wave trains through baroclinic energy conversion. On the other hand, the meridional winds organized by the wave trains can transfer energy and water vapor meridionally, highlighting the roles of intraseasonal oscillations in the extratropics. These issues deserve further investigations.

Acknowledgments. The authors thank the editor and reviewers for their constructive and detailed comments, which greatly improve the presentation. This work was supported by the National Natural Science Foundation of China (Grant 41721004).

\section{REFERENCES}

Alexander, M. A., and J. D. Scott, 1997: Surface flux variability over the North Pacific and North Atlantic Oceans. J. Climate, 10, 2963-2978, https://doi.org/10.1175/1520-0442(1997)010<2963: SFVOTN $>2.0 . \mathrm{CO} ; 2$.

Ambrizzi, T., B. J. Hoskins, and H.-H. Hsu, 1995: Rossby wave propagation and teleconnection patterns in the austral winter. J. Atmos. Sci., 52, 3661-3672, https://doi.org/10.1175/15200469(1995)052<3661:RWPATP > 2.0.CO;2.

Blackmon, M. L., Y. H. Lee, and J. M. Wallace, 1984: Horizontal structure of 500-mb height fluctuations with long, intermediate, and short time scales. J. Atmos. Sci., 41, 961-979, https://doi.org/ 10.1175/1520-0469(1984)041<0961:HSOMHF>2.0.CO;2.

Chen, P., and M. Newman, 1998: Rossby wave propagation and the rapid development of upper-level anomalous anticyclones during the 1988 U.S. drought. J. Climate, 11, 2491-2504, https://doi.org/ 10.1175/1520-0442(1998)011<2491:RWPATR > 2.0.CO;2.

Dai, Y., S. B. Feldstein, B. Tan, and S. Lee, 2017: Formation mechanisms of the Pacific-North American teleconnection with and without its canonical tropical convection pattern. J. Climate, 30, 3139-3155, https://doi.org/10.1175/JCLI-D-16-0411.1.

Dee, D. P., and Coauthors, 2011: The ERA-Interim reanalysis: Configuration and performance of the data assimilation system. Quart. J. Roy. Meteor. Soc., 137, 553-597, https://doi.org/ 10.1002/qj.828.

Ding, Q. H., and B. Wang, 2007: Intraseasonal teleconnection between the summer Eurasian wave train and the Indian monsoon. J. Climate, 20, 3751-3767, https://doi.org/10.1175/ JCLI4221.1.

Doblas-Reyes, F. J., M. Déqué, F. Valero, and D. B. Stephenson, 1998: North Atlantic wintertime intraseasonal variability and its sensitivity to GCM horizontal resolution. Tellus, $\mathbf{5 0 A}, 573-$ 595, https://doi.org/10.3402/tellusa.v50i5.14560.

Duchon, C. E., 1979: Lanczos filtering in one and two dimensions. J. Appl. Meteor., 18, 1016-1022, https://doi.org/10.1175/15200450(1979)018<1016:LFIOAT > 2.0.CO;2.
Elsner, J., 1992: A description of low-frequency atmospheric oscillations over the extratropical Northern Hemisphere using singular spectrum analysis. Geophys. Res. Lett., 19, 1775-1778, https://doi.org/10.1029/92GL01880.

Enomoto, T., B. J. Hoskins, and Y. Matsuda, 2003: The formation mechanism of the Bonin high in August. Quart. J. Roy. Meteor. Soc., 129, 157-178, https://doi.org/10.1256/qj.01.211.

Ferreira, R. N., W. H. Schubert, and J. J. Hack, 1996: Dynamical aspects of twin tropical cyclones associated with the MaddenJulian oscillation. J. Atmos. Sci., 53, 929-945, https://doi.org/ 10.1175/1520-0469(1996)053<0929:DAOTTC >2.0.CO;2.

Fukutomi, Y., K. Masuda, and T. Yasunari, 2012: Spatiotemporal structures of the intraseasonal oscillations of precipitation over northern Eurasia during summer. Int. J. Climatol., 32, 710-726, https://doi.org/10.1002/joc.2293.

Hall, J. D., A. J. Matthews, and D. J. Karoly, 2001: The modulation of tropical cyclone activity in the Australian region by the MaddenJulian oscillation. Mon. Wea. Rev., 129, 2970-2982, https://doi.org/ 10.1175/1520-0493(2001)129<2970:TMOTCA > 2.0.CO;2.

He, J., H. Lin, and Z. Wu, 2011: Another look at influences of the Madden-Julian oscillation on the wintertime East Asian weather. J. Geophys. Res., 116, D03109, https://doi.org/ 10.1029/2010JD014787.

Ho, C.-H., J.-H. Kim, J.-H. Jeong, H.-S. Kim, and D. Chen, 2006: Variation of tropical cyclone activity in the south Indian Ocean: El Niño-Southern oscillation and Madden-Julian oscillation effects. J. Geophys. Res., 111, D22101, https://doi.org/ 10.1029/2006JD007289.

Hong, X., R. Lu, and S. Li, 2018: Differences in the Silk Road pattern and its relationship to the North Atlantic Oscillation between early and late summers. J. Climate, 31, 9283-9292, https://doi.org/10.1175/JCLI-D-18-0283.1.

Hoskins, B. J., and T. Ambrizzi, 1993: Rossby wave propagation on a realistic longitudinally varying flow. J. Atmos. Sci., 50, 1661-1671, https://doi.org/10.1175/1520-0469(1993)050<1661: RWPOAR $>2.0 . \mathrm{CO} ; 2$.

Hsu, H.-H., 1996: Global view of the intraseasonal oscillation during northern winter. J. Climate, 9, 2386-2406, https://doi.org/10.1175/ 1520-0442(1996)009<2386:GVOTIO > 2.0.CO;2.

Hu, K. M., G. Huang, R. G. Wu, and L. Wang, 2018: Structure and dynamics of a wave train along the wintertime Asian jet and its impact on East Asian climate. Climate Dyn., 51, 4123-4137, https://doi.org/10.1007/s00382-017-3674-1.

Huang, R., and F. Sun, 1992: Impacts of the tropical western Pacific on the East Asian summer monsoon. J. Meteor. Soc. Japan, 70, 243-256, https://doi.org/10.2151/jmsj1965.70.1B_243.

Jeong, J.-H., C.-H. Ho, B.-M. Kim, and W.-T. Kwon, 2005: Influence of the Madden-Julian oscillation on wintertime surface air temperature and cold surges in East Asia. J. Geophys. Res., 110, D11104, https://doi.org/10.1029/2004JD005408.

—_, B.-M. Kim, C.-H. Ho, and Y.-H. Noh, 2008: Systematic variation in wintertime precipitation in East Asia by MJOinduced extratropical vertical motion. J. Climate, 21, 788-801, https://doi.org/10.1175/2007JCLI1801.1.

Jia, X., L. Chen, F. Ren, and C. Li, 2011: Impacts of the MJO on winter rainfall and circulation in China. Adv. Atmos. Sci., 28, 521-533, https://doi.org/10.1007/s00376-010-9118-z.

Jiang, X., and N.-C. Lau, 2008: Intraseasonal teleconnection between North American and western North Pacific monsoons with 20-day time scale. J. Climate, 21, 2664-2679, https:// doi.org/10.1175/2007JCLI2024.1.

—, M. Zhao, and D. E. Waliser, 2012: Modulation of tropical cyclones over the eastern Pacific by the intraseasonal variability 
simulated in an AGCM. J. Climate, 25, 6524-6538, https://doi.org/ 10.1175/JCLI-D-11-00531.1.

Jiao, Y., R. G. Wu, and L. Song, 2019: Individual and combined impacts of two Eurasian wave trains on intraseasonal East Asian winter monsoon variability. J. Geophys. Res., 124, 45304548, https://doi.org/10.1029/2018JD029953.

Kawamura, R., T. Murakami, and B. Wang, 1996: Tropical and mid-latitude 45-day perturbations over the western Pacific during the northern summer. J. Meteor. Soc. Japan, 74, 867890, https://doi.org/10.2151/jmsj1965.74.6_867.

Kong, X., J. Mao, and G. Wu, 2017: Influence on the South China rainfall anomalies of the atmospheric quasi-biweekly oscillation in mid-high latitude during the summer of 2002 (in Chinese). Chin. J. Atmos. Sci., 41, 1204-1220.

Kosaka, Y., and H. Nakamura, 2006: Structure and dynamics of the summertime Pacific-Japan teleconnection pattern. Quart. J. Roy. Meteor. Soc., 132, 2009-2030, https://doi.org/10.1256/qj.05.204.

,-- M. Watanabe, and M. Kimoto, 2009: Analysis on the dynamics of a wave-like teleconnection pattern along the summertime Asian jet based on a reanalysis dataset and climate model simulations. J. Meteor. Soc. Japan, 87, 561-580, https://doi.org/10.2151/jmsj.87.561.

Kushnir, Y., 1987: Retrograding wintertime low-frequency disturbances over the North Pacific Ocean. J. Atmos. Sci., 44, 2727-2742, https:// doi.org/10.1175/1520-0469(1987)044<2727:RWLFDO>2.0.CO;2.

Lau, K. M., and H. Y. Weng, 2002: Recurrent teleconnection patterns linking summertime precipitation variability over East Asia and North America. J. Meteor. Soc. Japan, 80, 1309-1324, https://doi.org/10.2151/jmsj.80.1309.

L'Heureux, M. L., and R. W. Higgins, 2008: Boreal winter links between the Madden-Julian oscillation and the Arctic Oscillation. J. Climate, 21, 3040-3050, https://doi.org/ 10.1175/2007JCLI1955.1.

Liu, H., M. Wen, J. He, and R. Zhang, 2012: Characteristics of the northeast cold vortex at intraseasonal timescale and its impact (in Chinese). Chin. J. Atmos. Sci., 36, 959-973.

Lofverstrom, M., 2020: A dynamic link between high-intensity precipitation events in southwestern North America and Europe at the Last Glacial Maximum. Earth Planet. Sci. Lett., 534, 116081, https://doi.org/10.1016/j.epsl.2020.116081.

Lu, R.-Y., J.-H. Oh, and B.-J. Kim, 2002: A teleconnection pattern in upper-level meridional wind over the North African and Eurasian continent in summer. Tellus, 54A, 44-55, https:// doi.org/10.3402/tellusa.v54i1.12122.

Madden, R. A., and P. R. Julian, 1971: Detection of a 40-50 day oscillation in the zonal wind in the tropical Pacific. J. Atmos. Sci., 28, 702-708, https://doi.org/10.1175/1520-0469(1971) 028<0702:DOADOI $>2.0$. CO 2 .

Maloney, E. D., and D. L. Hartmann, 2000: Modulation of eastern North Pacific hurricanes by the Madden-Julian oscillation. J. Climate, 13, 1451-1460, https://doi.org/10.1175/1520-0442(2000) 013<1451:MOENPH>2.0.CO;2.

Marcus, S. L., M. Ghil, and J. O. Dickey, 1996: The extratropical 40day oscillation in the UCLA general circulation model. Part II: Spatial structure. J. Atmos. Sci., 53, 1993-2014, https://doi.org/ 10.1175/1520-0469(1996)053<1993:TEDOIT>2.0.CO;2.

Mo, K. C., 1999: Alternating wet and dry episodes over California and intraseasonal oscillations. Mon. Wea. Rev., 127, 2759-2776, https:// doi.org/10.1175/1520-0493(1999)127<2759:AWADEO>2.0.CO;2.

Nitta, T., 1987: Convective activities in the tropical western Pacific and their impact on the Northern Hemisphere summer circulation. J. Meteor. Soc. Japan, 65, 373-390, https://doi.org/ 10.2151/jmsj1965.65.3_373.
Park, T.-W., C.-H. Ho, S. Yang, and J.-H. Jeong, 2010: Influences of Arctic Oscillation and Madden-Julian oscillation on cold surges and heavy snowfalls over Korea: A case study for the winter of 2009-2010. J. Geophys. Res., 115, D23122, https:// doi.org/10.1029/2010JD014794.

Plaut, G., and R. Vautard, 1994: Spells of low-frequency oscillations and weather regimes in the Northern Hemisphere. J. Atmos. Sci., 51, 210-236, https://doi.org/10.1175/15200469(1994)051<0210:SOLFOA > 2.0.CO;2.

Ren, X., X.-Q. Yang, and H. Hu, 2017: Subseasonal variations of wintertime North Pacific evaporation, cold air surges, and water vapor transport. J. Climate, 30, 9475-9491, https:// doi.org/10.1175/JCLI-D-17-0140.1.

Sato, N., and M. Takahashi, 2003: Formation mechanism of vorticity anomalies on the subtropical jet in the midsummer Northern Hemisphere. Theor. Appl. Mech. Japan, 52, 109115, https://doi.org/10.11345/nctam.52.109.

Simonnet, E., and G. Plaut, 2001: Space-time analysis of geopotential height and SLP, intraseasonal oscillations, weather regimes, and local climates over the North Atlantic and Europe. Climate Res., 17, 325-342, https://doi.org/10.3354/cr017325.

Stan, C., and V. Krishnamurthy, 2019: Intra-seasonal and seasonal variability of the Northern Hemisphere extra-tropics. Climate Dyn., 53, 4821-4839, https://doi.org/10.1007/s00382-019-04827-9.

Tanaka, S., K. Nishii, and H. Nakamura, 2016: Vertical structure and energetics of the western Pacific teleconnection pattern. J. Climate, 29, 6597-6616, https://doi.org/10.1175/JCLI-D-150549.1.

Teng, H., and G. Branstator, 2017: Causes of extreme ridges that induce California droughts. J. Climate, 30, 1477-1492, https:// doi.org/10.1175/JCLI-D-16-0524.1.

,,-- H. Wang, G. A. Meehl, and W. M. Washington, 2013: Probability of U.S. heat waves affected by a subseasonal planetary wave pattern. Nat. Geosci., 6, 1056-1061, https:// doi.org/10.1038/ngeo1988.

Vitart, F., A. W. Robertson, and D. L. T. Anderson, 2012: Subseasonal to Seasonal Prediction Project: Bridging the gap between weather and climate. WMO Bull., 61, 23-28.

Wang, B., P. Webster, K. Kikuchi, T. Yasunari, and Y. J. Qi, 2006: Boreal summer quasi-monthly oscillation in the global tropics. Climate Dyn., 27, 661-675, https://doi.org/10.1007/s00382-0060163-3.

Wang, L., T. Li, T. J. Zhou, and X. Y. Rong, 2013: Origin of the intraseasonal variability over the North Pacific in boreal summer. J. Climate, 26, 1211-1229, https://doi.org/10.1175/ JCLI-D-11-00704.1.

Wei, W., W. H. Li, Y. Deng, and S. Yang, 2019: Intraseasonal variation of the summer rainfall over the southeastern United States. Climate Dyn., 53, 1171-1183, https://doi.org/10.1007/ s00382-018-4345-6.

Wheeler, M. C., H. H. Hendon, S. Cleland, H. Meinke, and A. Donald, 2009: Impacts of the Madden-Julian oscillation on Australian rainfall and circulation. J. Climate, 22, 1482-1498, https://doi.org/10.1175/2008JCLI2595.1.

Wirth, V., M. Riemer, E. K. M. Chang, and O. Martius, 2018: Rossby wave packets on the midlatitude waveguide-A review. Mon. Wea. Rev., 146, 1965-2001, https://doi.org/10.1175/ MWR-D-16-0483.1.

Xin, X., S. Zeng, and S. Yao, 2017: The intraseasonal oscillations of the winter geopotential height over the North Pacific and its diagnosis (in Chinese). Trans. Atmos. Sci., 40, 280-287.

Xiong, Y., Q. Chen, and X. Ren, 2019: Influence of boreal winter intraseasonal variation of Aleutian low on water vapor 
transport and atmospheric rivers. Atmosphere, 10, 49, https:// doi.org/10.3390/atmos10020049.

Xu, P., L. Wang, and W. Chen, 2019: The British-Baikal Corridor: A teleconnection pattern along the summertime polar front jet over Eurasia. J. Climate, 32, 877-896, https://doi.org/10.1175/ JCLI-D-18-0343.1.

Yang, S., and T. Li, 2016: Intraseasonal variability of air temperature over the mid-high latitude Eurasia in boreal winter. Climate Dyn., 47, 2155-2175, https://doi.org/10.1007/s00382-015-2956-8.

— B. Bu, R. Zhang, and S. Zhou, 2013: The zonal propagating characteristics of low-frequency oscillation over the Eurasian mid-high latitude in boreal summer. Sci. China Earth Sci., 56, 1566-1575, https://doi.org/10.1007/s11430-012-4576-z.

Yao, C., Q. Huang, B. Zhu, and F. Liu, 2018: The 10-30-day oscillation of winter zonal wind in the entrance region of the East Asian subtropical jet and its relationship with precipitation in southern China. Dyn. Atmos. Oceans, 82, 76-88, https:// doi.org/10.1016/j.dynatmoce.2018.05.001.

Yao, S., K. Gong, and C. Zhao, 2016: Intraseasonal oscillation of the winter geopotential height in the middle latitude of Northern Hemisphere (in Chinese). J. Meteor. Sci., 36, 622-628.
Yasunari, T., 1979: Cloudiness fluctuations associated with the Northern Hemisphere summer monsoon. J. Meteor. Soc. Japan, 57, 227-242, https://doi.org/10.2151/jmsj1965.57.3_ 227.

Zhang, C., 2013: Madden-Julian oscillation: Bridging weather and climate. Bull. Amer. Meteor. Soc., 94, 1849-1870, https:// doi.org/10.1175/BAMS-D-12-00026.1.

Zhang, L., B. Wang, and Q. Zeng, 2009: Impact of the MaddenJulian oscillation on summer rainfall in southeast China. J. Climate, 22, 201-216, https://doi.org/10.1175/2008JCLI1959.1.

Zhang, S., and X. Ren, 2017: Low-frequency variability of the Aleutian low and its related synoptic transient eddy dynamic process (in Chinese). J. Meteor. Sci., 37, 1-9.

Zhu, Y., Z. Wen, Y. Guo, R. Chen, X. Li, and Y. Qiao, 2020: The characteristics and possible growth mechanisms of the quasibiweekly Pacific-Japan teleconnection in boreal summer. Climate Dyn., 55, 3363-3380, https://doi.org/10.1007/s00382020-05448-3.

Zwiers, F. W., and H. V. Storch, 1995: Taking serial correlation into account in tests of the mean. J. Climate, 8, 336-351, https:// doi.org/10.1175/1520-0442(1995)008<0336:TSCIAI >2.0.CO;2. 